\title{
ESTUDO DE CASO LUSO-BRASILEIRO SOBRE POLÍTICAS E PRÁTICAS DE EXPATRIAÇÃ̃O
}

\section{LUSO-BRAZILIAN CASE STUDY ON EXPATRIATION POLICIES AND PRACTICES}

\section{ESTUDIO DE CASO LUSO-BRASILEÑO SOBRE POLÍTICAS Y PRÁCTICAS DE EXPATRACIÓN}

\section{Shalimar Gallon}

Doutora em Administração - Universidade

Federal do Rio Grande do Sul, Porto Alegre,

Brasil

Professora e Pesquisadora da Faculdade

Meridional - IMED - Passo Fundo - RS - Brasil

shalimargallon@gmail.

\section{Aline Mendonça Fraga}

Mestra - Escola de Administração da

Universidade Federal do Rio Grande do Sul, Porto

Alegre, Brasil

Doutoranda - Escola de Administração da

Universidade Federal do Rio Grande do Sul, Porto

Alegre, Brasil

alinemf.adm@gmail.com

\section{Elaine Di Diego Antunes}

Doutora em Administração - Universidade

Federal do Rio Grande do Sul, Porto Alegre,

Brasil

Professora e Pesquisadora da Universidade

Federal do Rio Grande do Sul, Porto Alegre,

Brasil

elaine.antunes@ufrgs.br
Contextus

ISSNe 2178-9258

Organização: Comitê Científico Interinstitucional Editor-Chefe: Diego de Queiroz Machado

Editora Associada: Márcia Zabdiele Moreira

Avaliação: double blind review pelo SEER/OJS

Recebido em 12/07/2018

Aceito em 19/09/2018

$2^{a}$ versão aceita em 24/09/2018

http://dx.doi.org/10.19094/contextus.v17i1.33050

\section{RESUMO}

A expatriação é um processo corrente na condução dos negócios internacionais, auxiliando na interface e no alinhamento de políticas e práticas da Gestão de Pessoas com a estratégia empresarial, e tem, portanto, importância na sua expansão global. Essa pesquisa se constitui em estudo de caso qualitativo em uma empresa brasileira e outra portuguesa. A coleta de dados ocorreu por meio de um roteiro semiestruturado, contemplando 30 entrevistas. Foi utilizado o software Max-Qda (2007) para auxiliar a organização das categorias de análise com baseada na técnica de análise de conteúdo. O estudo aponta que há diferentes políticas e práticas de expatriação para as empresas pesquisadas, influenciadas pelo contexto do país de origem, legislação, estratégia e amadurecimento internacional da organização e objetivo da expatriação.

Palavras-chave: políticas; práticas; expatriação; internacionalização; gestão de pessoas.

\section{ABSTRACT}

Expatriation is a common process in international business, assisting in the interface and alignment of policies and practices of Human Resource Management with the business strategy, and therefore it is highly important in global expansion. This is a qualitative study case with a Brazilian and Portuguese company. The data were collected through semi-structured interviews with 30 interviewed. In addition, the software Max-Qda (2007) was used to assist the organization of categories of analysis based on the content analysis technique. The study shows 
that there are different policies and practices of expatriation to the surveyed companies influenced by the country context, legislation, strategy and international maturity of the organization and purpose of the expatriation.

Keywords: policies; practices; expatriation; internationalization; human resources management.

\section{RESUMEN}

La expatriación es un proceso corriente en la conducción de los negocios internacionales, ayudando en la interfaz y en la alineación de políticas y prácticas de la Gestión de Personas con la estrategia empresarial, y tiene, por lo tanto, importancia en su expansión global. Esta investigación constituye un estudio de caso cualitativo en una empresa brasilera y una portuguesa. La recolección de datos fue desarrollada por medio de un itinerario semiestructurado, con la realización de 30 entrevistas. El análisis de datos fue realizado con el software MaxQda (2007) para ayudar a organizar las categorías que fueron basadas en la técnica de análisis de contenido. El estudio apunta que hay diferentes políticas y prácticas de expatriación para las empresas encuestadas influenciadas por el contexto del país de origen, legislación, estrategia y maduración internacional de la organización y objetivo de la expatriación.

Palabras clave: políticas; prácticas; expatriación; internacionalización; gestión de personas.

\section{INTRODUÇÃO}

A expatriação é um processo corrente na condução dos negócios internacionais, auxiliando na interface e no alinhamento de políticas da Gestão de Pessoas (GP) com a estratégia empresarial. Sua expansão advém da economia global estável, que facilita a movimentação de pessoas internacionalmente (BROOKFIELD GLOBAL RELOCATION SERVICES, 2013). Esse processo normalmente acontece quando as empresas buscam desenvolver a liderança dos executivos, expandir novos mercados, adquirir conhecimento dos indivíduos, aumentar a participação dos mercados de atuação e transferir tecnologia (TANURE; EVANS; PUCIK, 2007). Devido à sua amplitude e à riqueza de conhecimento envolvido, a expatriação desempenha relevante papel na condução dos negócios e no direcionamento das estratégias internacionais.

À medida que ocorre o aumento do número de profissionais expatriados, ressalta-se a expatriação como opção estratégica para estruturar o modelo de gestão, enfatizando sua relevância nas decisões estratégicas, tanto no desenvolvimento individual como no organizacional (BIANCHI, 2011). Da mesma forma, Nunes, Vasconcelos e Jaussaud (2008) defendem que a expatriação se insere no âmbito organizacional, ligando a GP à gestão estratégica. A expatriação demanda, portanto, que suas políticas e práticas estejam alinhadas às estratégias da empresa (TANURE; EVANS; PUCIK, 2007), por estar relacionada ao negócio de forma integral e não somente com a GP.

Em face da informalidade das políticas e práticas de GP, o processo de expatriação é dificultado quando associado a um reconhecimento precário da posição estratégica desse processo (VIANNA; SOUZA, 2009; VIANNA, 2008). A desconexão entre a estratégia de 
internacionalização da empresa e o processo de expatriação (independentemente das etapas do processo) implica a marginalização de um trabalho estratégico entre a empresa e suas subsidiárias (VIANNA; SOUZA, 2009). É justificável, pois, analisar políticas e práticas de expatriação para compreender de que maneira o processo pode auxiliar na condução estratégica da internacionalização.

Há, portanto, lacunas na literatura que revelam a necessidade de melhor compreender as políticas e práticas de expatriação. Por isso, indaga-se: quais políticas e práticas de GP são importantes no processo de expatriação? Assim, o presente estudo buscou identificar e analisar as políticas e práticas da GP de expatriação em uma empresa brasileira e uma empresa portuguesa em função da proximidade cultural e linguística dos dois países, além do vínculo histórico que permitiu maior riqueza e aprofundamento da investigação.

Nas próximas seções, aborda-se a literatura pertinente, seguida dos procedimentos metodológicos da pesquisa. A quarta seção apresenta a análise de dados, e a última, as considerações finais do presente estudo.

\section{POLÍtiCAS E PRÁTICAS DE EXPATRIAÇÃO}

À medida que os mercados internacionais ampliam as possibilidades de atuação no exterior, crescem as pesquisas buscando analisar as estratégias de internacionalização empresarial (ARMAGAN; FERREIRA, 2005; BHATTACHARYYA; JHA, 2017; MARANO et al., 2016). Decisões estratégicas internacionais podem incluir a opção dos modos de entrada, como alianças estratégicas, joint ventures ou aquisições internacionais, a adaptação do portfólio de produtos para exportar ou operações de investimento estrangeiro e a escolha sobre quem contratar para gerenciar as subsidiárias no exterior - locais ou expatriados (ARMAGAN; FERREIRA, 2005).

Importa saber que, entre os maiores desafios para a internacionalização de empresas, estão a seleção e o desenvolvimento de profissionais subsidiários estrangeiros. Ao implementar uma estratégia de internacionalização, é necessário criar práticas e políticas dinâmicas, bem como um sistema de trabalho que desenvolva o sistema estratégico de GP (HARVEY; SPEIER; NOVICEVIC, 2002).

Para traçar um panorama atualizado sobre as políticas e prática de expatriação, expõese um levantamento das políticas e práticas de expatriação realizado em periódicos da CAPES 
no período de 2008 a 2012 (GALLON; ANTUNES, 2015). Conforme o levantamento, as políticas e práticas que valorizam a transferência de conhecimento e a imposição de políticas e práticas da matriz à subsidiária são os temas de maior destaque nos estudos analisados. Outros artigos expõem a análise específica de uma prática tais como de seleção, treinamento, gestão de desempenho, remuneração, adaptação cultural e retorno financeiro (GALLON; ANTUNES, 2015). Esse levantamento aponta que, de modo geral, não há consenso sobre quais políticas e práticas fazem parte do processo de expatriação, mas o que frequentemente se encontra na literatura são as políticas de recrutamento e seleção; remuneração; treinamento (linguístico e cultural) do expatriado e de sua família; e gestão de carreira. Em relação às práticas, as que mais se destacam são: objetivos da expatriação; análise do perfil familiar; preparação da documentação do expatriado e de sua família; análise da saúde do expatriado e de sua família; esclarecimento das expectativas e das metas de desempenho; apoio logístico; e apoio psicológico.

Ademais, as seguintes temáticas podem ser citadas como de destaque na literatura nacional e internacional acerca do fenômeno da expatriação: remuneração e benefícios (HOMEM; TOLFO, 2008; ORSI; FISCHER, 2011); interculturalidade (FREITAS, 2008; CRAIDE; SILVA, 2012; MACHADO; STREHAU, 2008; FREITAS; DANTAS, 2011; CRAIDE; ABDALA; BRITO, 2010; CRAIDE et al., 2011; MAO; SHEN, 2015); gestão de carreira (GALLON; SCHEFFER; BITENCOURT, 2013; BIANCHI, 2011; RAMASWAMI; CARTER; DREHER, 2016; TAKEUCHI; WANG, 2018); expatriação e repatriação (LIMA; BRAGA, 2010; HOMEM; DELLAGNELO, 2006; IRIGARAY; VERGARA, 2010; VIANNA; SOUZA, 2009; NUNES; VASCONCELOS; JAUSSAUD, 2008; FREITAS, 2010; DAME et al., 2011; SPOHR; FLEURY, 2011); adaptação cultural (GONZÁLEZ et al., 2011; KUBO; BRAGA, 2013; ARAUJO; NUNES, 2012; CARPES et al., 2011; ZHANG, 2013); distância psíquica (TANURE; BARCELLOS; FLEURY, 2009; TEIXEIRA; SILVA; LESSA, 2011; HEMMASI; DOWNES, 2013); gestão de competências (REIS, 2012; LISBOA; BRUNSTEIN, 2010); equipes multiculturais (BUENO; FREITAS, 2012; ORSI; BERTOIA, 2012; HAAK-SAHEEM, 2016); e gestão do conhecimento (ROCHA; BORINI, 2008).

Pelo interesse do artigo, ressalta-se o estudo de Lima e Braga (2010) que relata o levantamento de políticas e práticas de GP utilizadas pelas empresas no Brasil, para garantir o sucesso do processo de repatriação e retenção dos repatriados. Conforme as autoras, as ações das empresas na repatriação não são estratégicas como recomendado (LAZAROVA; CALIGIURI, 2004) e estão relacionadas com o suporte operacional ao repatriado. Não são 
adotadas políticas e práticas que poderiam solucionar ou minimizar os principais problemas enfrentados pelos repatriados, pois - ainda que a maioria das empresas brasileiras possua políticas de repatriação estruturadas e documentadas - não são, em geral, divulgadas aos empregados. Os resultados da pesquisa mostram que as principais políticas e práticas de GP para a repatriação são: manter o expatriado informado sobre as mudanças que ocorrem na organização, durante a expatriação; pagar viagens ao país de origem durante o período no exterior; disponibilizar verba para realização da mudança; apoiar o processo de expatriação; recolocar o expatriado no mercado de trabalho, se não houver um posto apropriado no retorno. Algumas dessas políticas e práticas são adotadas apenas parcialmente como, por exemplo, a comunicação que se evidencia deficiente na maioria das empresas.

A falta de políticas para a repatriação é justificada quer pelo foco no envio de expatriados para o exterior e não na repatriação, quer pelo número muito baixo de repatriados, ou ainda porque os brasileiros não têm dificuldades de adaptação na expatriação, nem no retorno ao país de origem. Isso reflete uma miopia da GP e dos gestores em geral, ao não saberem identificar o que a empresa perde, em termos de conhecimentos e competências, quando desliga um empregado com experiência internacional (GALLON; SCHEFFER; BITENCOURT, 2013; LIMA; BRAGA, 2010).

Devido à baixa valorização da etapa de repatriação e diante da sua importância para as empresas, tal fase tem sido foco de pesquisas. Considera-se falhas no processo quando o expatriado não deseja retornar da expatriação e quando, ao retornar, não permanece na organização (CHO; HUTCHINGS; MARCHANT, 2013). Osman-Gani e Hyder (2008) analisam a gestão de expatriados na região da Ásia, com ênfase na questão da adaptação na repatriação, buscando compreender as práticas de GP relativas à formação e ao desenvolvimento da adaptação efetiva dos gestores internacionais na repatriação. O estudo fornece informações sobre programas de repatriamento e formação; conteúdos de formação; duração do programa; modos de entrega; programas de treinamento eficazes. Os resultados mostram que $60 \%$ das empresas não têm nenhum programa formal de repatriamento para seus gestores internacionais, corroborando os estudos de Lima e Braga (2010), sendo as oportunidades de desenvolvimento de carreira e o suporte na mudança física as características preferenciais a serem incluídas no desenvolvimento de uma política de repatriamento.

A maioria das empresas parece pensar que, pelo fato de os empregados estarem voltando para seu próprio país, não há necessidade de fornecer acompanhamento. Greer e Stiles (2016) sugerem criar uma estratégia de desenvolvimento organizacional para a 
repatriação, valorizando os profissionais que já retornaram da experiência, avaliando o aprendizado e gerenciando a carreira após a reintegração ao país de origem. Palestras, workshops e seminários dentro do programa de treinamento foram sinalizados como práticas importantes, havendo preferência para que os programas sejam conduzidos por empregados de escritório residencial, com experiência em repatriação (OSMAN-GANI; HYDER, 2008; LIMA; BRAGA, 2010).

Já Vianna e Souza (2009) analisaram a importância da estruturação da expatriação como um processo que corresponda a um valor estratégico, em sete empresas brasileiras. Os entrevistados afirmaram que a área estava sendo reestruturada para alcançar esse valor. Aparentemente, essa reestruturação está ocorrendo há anos: apesar de não serem as mesmas empresas, é um padrão de resposta encontrado em outros estudos (VIANNA, 2008; LIMA; BRAGA, 2010). As pesquisas que buscam questionar a estrutura da GP para apoiar a expatriação acabam encontrando áreas em desenvolvimento ou a serem desenvolvidas.

\section{PROCEDIMENTOS METODOLÓGICOS}

O presente estudo utilizou como estratégia de pesquisa o estudo de caso (YIN, 2010) de caráter qualitativo. A pesquisa foi realizada na empresa brasileira Elétrica (sua matriz no Brasil e sua subsidiária em Portugal) e na empresa portuguesa Plástico (sua matriz em Portugal e sua subsidiária no Brasil) (nomes fictícios). As empresas foram escolhidas, pois ambas têm destaque no país de origem, pertencem ao setor industrial, estão internacionalizadas há mais de 20 anos e encontram-se presentes em diversos países.

A primeira parte da coleta de dados começou em um estudo exploratório com gestores e expatriados brasileiros e portugueses no intuito de fazer um levantamento sobre o panorama da internacionalização empresarial, bem como entender o contexto português. As empresas portuguesas, sediadas em Lisboa, que participaram do estudo exploratório receberam o nome fictício de Grupo Turismo, Empresa Energia, Empresa Cimento e Empresa Exportação. Em cada empresa foi entrevistada uma pessoa, a fim de melhor compreender o processo de internacionalização e a relação com a expatriação. Já as empresas brasileiras pesquisadas foram a Metálica (Rio Grande do Sul) e a Ferro (Rio Grande do Sul). Na Metálica, foram entrevistadas três pessoas e, na Ferro, duas. Também foi entrevistada uma consultora em intercâmbio cultural, com renome na área sobre mobilidade internacional em grandes empresas, que atua no estado de Santa Catarina. 
Buscou-se entrevistar pessoas que houvessem sido expatriadas para Portugal ou Brasil e tivessem conhecimento ou contato com a expatriação, gestão de pessoas, estratégia, internacionalização ou com os países pesquisados. No entanto, o número de pessoas disponíveis para serem entrevistadas mostrou-se reduzido e não foi usado, portanto, nenhum critério adicional de escolha dos entrevistados (como sexo, idade ou cargo). Todas as pessoas indicadas pelas empresas e pelos entrevistados foram contatadas para participarem da pesquisa, cabendo a elas aceitar ou não contribuir com o estudo. Assim, também fizeram parte da pesquisa os expatriados que estavam em outras subsidiárias, fora do contexto PortugalBrasil, mas que possuíam experiência e conhecimento internacional e sobre expatriação.

Para a segunda parte da coleta dos dados, foram realizadas entrevistas com um roteiro semiestruturado, desenhado a partir do referencial teórico exposto na presente pesquisa, que foi sendo organizado conforme a exploração do campo. Foram utilizadas ferramentas de conversação via internet, como o Skype, que oferece a possibilidade de entrevistas individuais (JANGHORBAN; ROUDSARI; TAGHIPOUR, 2014), para auxiliar na condução das entrevistas ou para retomar algum ponto da entrevista que precisava ser esclarecido, encontrando-se a pessoa distante geograficamente das pesquisadoras. Além das entrevistas, foram realizadas consultas a documentos, sites e material publicitário, com o objetivo de triangular os dados, no qual múltiplas fontes de informação são utilizadas, para melhor compreender o fenômeno que está sendo estudado (YIN, 2010), dando relevância igual para todos os dados (FLICK, 2002).

Relativamente às fases da coleta de dados, esta começou no Brasil com o estudo exploratório e, posteriormente, ocorreu em Portugal (entrevistados coadjuvantes e protagonistas das empresas portuguesas). No total, foram feitas 31 entrevistas: uma foi realizada pelo Jornal i (2011), em 12.12.2011, sendo assim, um dado secundário, e 30 são dados primários (Quadro 1). Desses dados primários, presencialmente ocorreram 12 entrevistas em Portugal e 16 no Brasil, além de duas entrevistas por Skype, totalizando 29 horas e 55 minutos de conversação. Dos entrevistados, 12 pessoas eram da GP; 17 eram expatriados; 16 eram gestores, considerando que alguns entrevistados eram da GP e expatriado, gestor e expatriado ou da GP e gestor. Nenhum dos entrevistados era da GP, gestor e expatriado. 
Quadro 1 - Perfil dos Entrevistados

\begin{tabular}{|c|c|c|c|}
\hline Nome & Cargo (atual) & Empresa & Observações \\
\hline E1 & $\begin{array}{l}\text { CEO e sócio- } \\
\text { fundador }\end{array}$ & $\begin{array}{l}\text { Plástico } \\
\text { Portugal }\end{array}$ & $\begin{array}{l}\text { Brasileiro, mas reside em Portugal desde } \\
\text { criança. Diversas } \\
\text { internacionais }\end{array}$ \\
\hline E2 & $\begin{array}{l}\text { CEO e sócio- } \\
\text { fundador }\end{array}$ & $\begin{array}{l}\text { Plástico } \\
\text { Portugal }\end{array}$ & $\begin{array}{l}\text { Entrevista cedida para o site Jornal i } \\
(2011) \text {, em 12.12.2011 }\end{array}$ \\
\hline E3 & $\begin{array}{l}\text { Gerente de GP } \\
\text { Portugal e Espanha }\end{array}$ & $\begin{array}{l}\text { Plástico } \\
\text { Portugal }\end{array}$ & Portuguesa, nunca foi expatriada \\
\hline E4 & $\begin{array}{l}\text { Analista de GP } \\
\text { Internacional }\end{array}$ & $\begin{array}{l}\text { Plástico } \\
\text { Portugal }\end{array}$ & $\begin{array}{l}\text { Português, trabalhou na Plástico da } \\
\text { Inglaterra (contratado local }- \text { um ano e } \\
\text { meio) e, hoje, trabalha na Plástico Portugal } \\
\text { ( } 3 \text { anos) }\end{array}$ \\
\hline E5 & $\begin{array}{l}\text { Diretor Geral de } \\
\text { Design }\end{array}$ & $\begin{array}{l}\text { Plástico } \\
\text { InLab Brasil }\end{array}$ & $\begin{array}{l}\text { Português, expatriado no Brasil há } 1 \text { ano, } \\
\text { casado com uma brasileira. Trabalhou no } \\
\text { Japão, Holanda e EUA (por outras } \\
\text { empresas) }\end{array}$ \\
\hline E6 & Analista de GP & $\begin{array}{l}\text { Plástico } \\
\text { Brasil } \\
\end{array}$ & Brasileira, nunca foi expatriada \\
\hline E7 & Gerente de GP & $\begin{array}{l}\text { Plástico } \\
\text { Brasil }\end{array}$ & Brasileiro, nunca foi expatriado \\
\hline E8 & $\begin{array}{l}\text { Gerente Geral das } \\
\text { unidades: Duque de } \\
\text { Caxias (RJ), São } \\
\text { Cristovão (RJ) e São } \\
\text { Paulo (SP) }\end{array}$ & $\begin{array}{l}\text { Plástico } \\
\text { Brasil }\end{array}$ & $\begin{array}{l}\text { Português, expatriado no Brasil há } 3 \text { anos. } \\
\text { Expatriado para Ucrânia, Canadá, Rússia e } \\
\text { Inglaterra }\end{array}$ \\
\hline E9 & $\begin{array}{l}\text { Supervisor } \\
\text { processos }\end{array}$ & $\begin{array}{l}\text { Plástico } \\
\text { Brasil }\end{array}$ & $\begin{array}{l}\text { Português, expatriado no Brasil há } 2 \text { anos } \\
\text { (um ano em SP e um ano em MG). Foi } \\
\text { expatriado para a Rússia, Ucrânia e Itália }\end{array}$ \\
\hline E10 & $\begin{array}{l}\text { Chefe de vendas } \\
\text { internacionais }\end{array}$ & $\begin{array}{l}\text { Elétrica } \\
\text { Brasil }\end{array}$ & $\begin{array}{l}\text { Brasileiro, foi expatriado por sete anos em } \\
\text { Portugal }\end{array}$ \\
\hline E11 & $\begin{array}{l}\text { Diretor de GP } \\
\text { Corporativa }\end{array}$ & $\begin{array}{l}\text { Elétrica } \\
\text { Brasil }\end{array}$ & Brasileiro, nunca foi expatriado \\
\hline E12 & Diretor Internacional & $\begin{array}{l}\text { Elétrica } \\
\text { Brasil }\end{array}$ & $\begin{array}{l}\text { Brasileiro, expatriado para China, } \\
\text { Alemanha e Portugal }\end{array}$ \\
\hline E13 & $\begin{array}{l}\text { Vice-Presidente de } \\
\text { Operações, Finanças } \\
\text { e TI }\end{array}$ & Elétrica EUA & $\begin{array}{l}\text { Brasileiro, expatriado há um ano e meio. Já } \\
\text { tinha experiência internacional anterior }\end{array}$ \\
\hline E14 & $\begin{array}{l}\text { Assistente técnico da } \\
\text { Regional Europeia }\end{array}$ & $\begin{array}{l}\text { Elétrica } \\
\text { Brasil }\end{array}$ & Brasileiro, expatriado há 4 anos e meio \\
\hline E15 & $\begin{array}{l}\text { Ex-Diretor } \\
\text { Internacional } \\
\text { (aposentado) }\end{array}$ & $\begin{array}{l}\text { Elétrica } \\
\text { Brasil }\end{array}$ & $\begin{array}{l}\text { Brasileiro e atuou no planejamento e } \\
\text { implantação da Elétrica nos cinco } \\
\text { continentes. }\end{array}$ \\
\hline E16 & $\begin{array}{l}\text { Analista de GP } \\
\text { Internacional }\end{array}$ & $\begin{array}{l}\text { Elétrica } \\
\text { Brasil }\end{array}$ & Brasileiro, nunca foi expatriado \\
\hline E17 & $\begin{array}{l}\text { Gerente de Mercado } \\
\text { Internacional }\end{array}$ & $\begin{array}{l}\text { Elétrica } \\
\text { Portugal }\end{array}$ & $\begin{array}{l}\text { Brasileiro, expatriado há } 7 \text { anos em } \\
\text { Portugal. Foi expatriado para a África do } \\
\text { Sul e EUA }\end{array}$ \\
\hline
\end{tabular}




\begin{tabular}{|c|c|c|c|}
\hline E18 & Analista de GP & $\begin{array}{l}\text { Elétrica } \\
\text { Portugal }\end{array}$ & Portuguesa, nunca foi expatriada \\
\hline E19 & Gerente de Vendas & $\begin{array}{l}\text { Elétrica } \\
\text { Portugal }\end{array}$ & $\begin{array}{l}\text { Brasileiro, expatriado há } 3 \text { anos, sem } \\
\text { experiência internacional anterior }\end{array}$ \\
\hline E20 & $\begin{array}{l}\text { Diretor de operações } \\
\text { internacionais }\end{array}$ & Metálica & $\begin{array}{l}\text { Brasileiro, foi expatriado para o México ( } 4 \\
\text { anos) e Índia ( } 3 \text { anos) }\end{array}$ \\
\hline E21 & Gerente Comercial & Metálica & $\begin{array}{l}\text { Brasileiro. Foi diretor expatriado da } \\
\text { empresa Metálica Portugal por } 3 \text { anos }\end{array}$ \\
\hline E22 & $\begin{array}{l}\text { Analista de GP } \\
\text { Corporativo }\end{array}$ & Metálica & $\begin{array}{l}\text { Brasileira, com experiência internacional, } \\
\text { mas não empresarial }\end{array}$ \\
\hline E23 & Analista de GP & Ferro & $\begin{array}{l}\text { Brasileira, morou no Japão e tem diversas } \\
\text { experiências internacionais. Atualmente, é } \\
\text { contratada local nos EUA }\end{array}$ \\
\hline E24 & $\begin{array}{l}\text { Ex-Vice-Diretor } \\
\text { Geral }\end{array}$ & Ferro & $\begin{array}{l}\text { Brasileiro, nunca expatriou, } 20 \text { anos em } \\
\text { cargos estratégicos de empresas } \\
\text { multinacionais }\end{array}$ \\
\hline E25 & $\begin{array}{l}\text { Assessora Técnica de } \\
\text { GP Corporativo }\end{array}$ & Ferro & Brasileira, foi expatriada para os EUA \\
\hline E26 & $\begin{array}{l}\text { Consultora } \\
\text { Treinamento } \\
\text { Intercultural } \\
\text { expatriação }\end{array}$ & Equipe Psico & $\begin{array}{l}\text { Brasileira, com intercâmbio de } 5 \text { anos na } \\
\text { Espanha e na Itália }\end{array}$ \\
\hline E27 & $\begin{array}{l}\text { CEO e sócio- } \\
\text { sociofundador }\end{array}$ & $\begin{array}{l}\text { Grupo } \\
\text { Turismo }\end{array}$ & Português e atua no mercado internacional \\
\hline E28 & $\begin{array}{lr}\begin{array}{lr}\text { Diretor } \\
\text { Atendimento }\end{array} & \mathrm{e} \\
\text { controle de gestão } & \\
\end{array}$ & Cimento & $\begin{array}{l}\text { Português, expatriado por } 4 \text { anos na } \\
\text { Espanha }\end{array}$ \\
\hline E29 & Gestor de Projetos & Energia & $\begin{array}{l}\text { Português, expatriado há } 5 \text { anos no Brasil. } \\
\text { Retornou para Portugal há } 8 \text { meses }\end{array}$ \\
\hline E30 & $\begin{array}{ll}\text { Representante } & \text { do } \\
\text { Conselho } & \text { de } \\
\text { Administração } & \\
\end{array}$ & Exportação & Portuguesa, nunca expatriada \\
\hline E31 & Cônsul Português & $\begin{array}{l}\text { Governo } \\
\text { Português }\end{array}$ & Português. \\
\hline
\end{tabular}

Fonte: elaboração própria.

Para analisar as informações, foi utilizada a técnica de análise de conteúdo (BARDIN, 2009). Após a coleta de dados, transcreveram-se as entrevistas e fez-se uma leitura flutuante dos dados a fim de estruturar as categorias. A análise partiu de quatro macrocategorias $a$ priori: GP, internacionalização, expatriação e diferenças entre os países, visto que esses foram os temas norteadores da pesquisa. Cabe ressaltar que, no presente estudo, será explorada somente a categoria de políticas e práticas de expatriação.

Conforme o trabalho de categorização era desenvolvido, as categorias primárias foram surgindo naturalmente e sendo organizadas com base no que foi abordado no referencial 
teórico, ou seja, de acordo com as políticas e práticas de expatriação encontradas. Durante e no final do processo de categorização, era realizada nova organização das categorias, caracterizando um processo contínuo. Para organização e reestruturação das categorias foi utilizado o software Max-Qda versão 2007.

\section{ANÁLISE E DISCUSSÃO DOS RESULTADOS}

A seguir será apresentada a Elétrica e, posteriormente, a Plástico, assim como as respectivas análises das informações coletadas. Por fim, é realizada uma análise descritiva e comparativa dos dois casos estudados.

\subsection{Estudo de Caso da Elétrica}

Fundada em 1961, a Elétrica é uma empresa de capital brasileiro atuante no setor eletrônico e com sede no estado de Santa Catarina. A empresa começou seu processo de internacionalização, em 1988, por meio de exportações e, em razão da meta de ser a maior fabricante de elétricos industriais do mundo, em 2002, adquiriu a empresa Motores, em Portugal, tradicional fabricante de elétricos especiais (EMPRESA ELÉTRICA, 2014).

A primeira expatriação realizada pela Elétrica foi, na década de 1990, para os Estados Unidos da América (EUA). Os entrevistados relatam as dificuldades em realizar esse processo, principalmente pela inexperiência internacional e pelo contexto brasileiro, caracterizado pela baixa tecnologia e pelo lento acesso às informações. Atualmente, a empresa conta com "uma política de práticas internacionais que é um documento super restrito e ele não é disponibilizado, só nós da GP temos acesso" (E16 - Analista de GPI Brasil). Essa restrição, apesar de não ter sido abordada diretamente nas entrevistas, ocorre para evitar conflitos entre os empregados internacionais por causa dos benefícios concedidos aos diferentes cargos e situações.

Conforme os processos de expatriação foram ficando frequentes, a empresa foi adquirindo experiência e aprimorando as viagens: "pelo menos, o meu processo acho que foi um pouquinho mais fácil, porque o processo já estava um pouco mais maduro" (E19 Gerente de Vendas Europa). A percepção de maior atuação da GP está relacionada com a reestruturação da GP Internacional (GPI) na matriz, que acaba "dando suporte a assuntos 
diversos de GP nas unidades do exterior" (E16 - Analista de GPI Brasil). O E13 (VicePresidente EUA) concorda com o entendimento de suporte da GPI, porque "tem muita gente que considera que, na expatriação, tu passas a ser um filho da empresa e eu acho que é um pouco de exagero". Essa perspectiva de amadurecimento da área corrobora os estudos de Vianna e Souza (2009), Vianna (2008) e Lima e Braga (2010) de que a GPI está se estruturando ao longo dos anos.

Os contratos de expatriação acabaram assumindo um caráter burocrático, bem como as políticas e práticas de expatriação abordadas por Vianna e Souza (2009) e Vianna (2008), mais no intuito de preservar a empresa do que para dar suporte aos empregados no exterior. Essa situação é visível neste relato: "eu nunca tive problema de doenças, de visto, de nada. Nunca tive que recorrer a eles. O dia que tiver alguma coisa, com certeza, eu vou recorrer e eles vão ter que me dar apoio" (E19 - Gerente de Vendas Europa). Isso mostra que nem mesmo os aspectos mais básicos, como a saúde, estão claramente explicitados, submetendo o empregado a possíveis contratempos.

A questão de treinamento, objetivo e retenção do expatriado ainda não está clara para a empresa e mostra diferentes vertentes. O E19 (Gerente de Vendas Europa), em sua percepção de expatriado, acredita que a empresa vê esse processo como uma forma de treinamento e desenvolvimento do empregado, a fim de incrementar o quadro da empresa pela experiência internacional da equipe, visando competir no cenário global. O entendimento da expatriação como um treinamento do empregado é uma política comum apontada por diversos autores (FREITAS, 2010; FREITAS; DANTAS, 2011), embora outros estudos (STROH, 1995; MCCALL; HOLLENBECK, 2003; GALLON; SCHEFFER; BITENCOURT, 2013) mostrem que o crescimento organizacional do expatriado nem sempre ocorre, o que deveria ser uma política, pois o objetivo da expatriação foi o desenvolvimento do empregado.

Esse contexto implica uma desvalorização do processo de expatriação, visto que não existe, após a repatriação, uma política formal de avaliação de desempenho do empregado, o que perpetua a dificuldade de gerir a carreira do indivíduo, questão primordial na experiência de expatriação (RAMASWAMI; CARTER; DREHER, 2016; TAKEUCHI; WANG, 2018). O E15 (Ex-Diretor Internacional Brasil) ressalta a importância de analisar o que essas pessoas estão agregando para a empresa, entretanto a avaliação da contribuição efetiva do empregado, como já observado, não é uma prática formalizada. O seu depoimento relata essa percepção: "se a pessoa é um executivo, é uma pessoa de potencial, é uma atitude. Se é um camarada que está descontente, que não contribui para o grupo, não faz nada para melhorar, tu tem que dar 
tratamento diferente. Claro, tem que ter uma política escrita e tal, mas isso aí não está resolvido".

Valorizar os expatriados é uma prática da empresa para o E12 (Diretor Internacional do Brasil), pois oportuniza melhores colocações no Brasil. No entanto, isso não depende só da empresa, mas da ocasião, pois é difícil conciliar as expectativas de todos os expatriados na repatriação. Ou seja, se existe uma oportunidade, a promoção ocorre; caso contrário, a pessoa fica à espera de uma oportunidade. Tal situação mostra o caráter informal do processo, ao contrário do recomendado por Greer e Stiles (2016), sobretudo em função da dinamicidade da empresa e da expatriação em si.

Esse contexto é influenciado pela dificuldade de gerir o desempenho dos expatriados, pois eles realizaram um trabalho no exterior e de gestores que lá se encontram. Quando chegam ao país de origem, não há a devida comunicação entre a filial e a matriz, dificultando o conhecimento sobre o rendimento do expatriado. Enfatiza-se, portanto, a carência de estudos para entender a gestão de desempenho de expatriados, visto que o levantamento de estudos sobre políticas e práticas de expatriação realizado por Gallon e Antunes (2015) não apresenta um estudo sobre a temática.

Sobre a dinamicidade e o imediatismo em torno da expatriação, o relato do E16 (Analista de GPI Brasil) mostra questões práticas que dificultam a ação da GP em relação à preparação da expatriação e a seus objetivos:

Ela [GPI] ainda é muito reativa nesse sentido [de dar treinamento], poderia preparar um pouco melhor as pessoas para isso. É um desafio grande. Seria o ideal para empresa, preparar as pessoas, fazer elas passarem por várias áreas antes, mas assim, eu acho que tu não vai achar muitas empresas no Brasil, não sei se no mundo, que vão dizer assim para ti: 'poxa, vou pegar, vou preparar uma pessoa em dois anos e mandar ela para fora'. Até tu preparar, em dois anos, essa pessoa já saiu da empresa (E16 Analista de GPI Brasil).

No entanto, algumas ações vêm sendo desenvolvidas para atender os expatriados, principalmente, os que vão a países com um contexto muito diferente daquele ao qual o brasileiro está acostumado. A fim de evitar o comodismo e a dependência da unidade em relação à matriz, o requerimento de um expatriado é avaliado com cautela. Isso também ocorre tanto pelo alto custo envolvido nessa movimentação como pela valorização da mão de obra local, como relata o E13 (Vice-Presidente EUA):

Se eu quero expatriar alguém, eu preciso submeter uma justificativa perante uma comissão de expatriação, que vai avaliar se aquela pessoa tem o perfil, se faz parte da política Elétrica, faz uma série de análises para garantir que eu não estou simplesmente exportando mão de obra para uma filial, principalmente, as pequenas; quando você se aperta é muito mais fácil pedir socorro para a matriz do que buscar no mercado. Mas não é tão simples assim. Essa comissão, antes de liberar esse cidadão no Brasil, faz toda essa análise para ir, qual é a vantagem, muitas vezes, a filial quer mão de obra barata, 
acontece, não vou negar, para isso existe o trabalho temporário. O trabalho temporário, se tu tem uma necessidade imediata, antes de expatriar, testa. O trabalho temporário te permite isso. Traz a pessoa por alguns meses, não faz um contrato de expatriação de longo prazo. Até para vida do cidadão né, imagina, tu traz o cara, não dá certo. E o contrato é 5 anos. Muitas vezes, tem que repor o cidadão, não é simplesmente descartar. Claro que eu estou exagerando.

Com base nesse panorama, políticas e práticas de expatriação destacam-se pelo caráter informal, propiciando descontentamento, desconfiança e impessoalidade no processo. Elucidam-se, a seguir, as principais práticas citadas e destacadas:

- $\quad$ análise do perfil, recrutamento e seleção: dificilmente há uma seleção aberta para todos os empregados. Havendo demanda da unidade ou necessidade corporativa em melhorar resultados e expandir a cultura da empresa, é indicado o cargo a ser preenchido. É realizado, então, o levantamento, principalmente por meio de indicação dos gestores, das pessoas com possibilidade de serem expatriadas. A partir disso, é feita a filtragem até restar um único candidato. Normalmente, os cargos a serem preenchidos são de gestão, o que diminui o número de candidatos disponíveis. Embora algumas expatriações tenham caráter emergencial, há, no entanto, uma tendência de as seleções serem realizadas com cautela para evitar o retorno precoce;

- análise do perfil familiar: não há. Depois que o expatriado foi escolhido, a família assume papel secundário: acompanhar o expatriado;

- auxílio e acompanhamento psicológico para o empregado e sua família: não é disponibilizado no contrato de expatriação, mas os entrevistados relataram que, quando solicitaram esse auxílio para a empresa, ele foi disponibilizado rapidamente;

- contrato: há um contrato que especifica salário e benefícios a serem recebidos e tempo de expatriação. Esse contrato é vinculado à empresa de origem. Não há quebra de vínculo empregatício;

- trabalho a ser desenvolvido: não há nada formalizado. Quando a proposta é realizada para o empregado, há uma conversa informal sobre o trabalho a ser assumido. No entanto, isso muda conforme o gestor que está coordenando o processo;

- remuneração e benefícios: $25 \%$ de aumento salarial obrigatório e alguma porcentagem relacionada ao cargo assumido (referente à quantia recebida no Brasil). São fixados diversos benefícios, como auxílio de custos, logística, mudança, carro, telefone, aluguel da casa, escola para os filhos, entre outros, de acordo com o cargo assumido. Alguns expatriados (tanto da Elétrica como da Metálica e da Ferro) recompensam financeiramente o cônjuge que sai do emprego no Brasil para acompanhar o expatriado. A Metálica, preocupada com um possível deslumbramento advindo do aumento salarial, 
disponibiliza assessoria financeira para o expatriado fazer seu planejamento financeiro. $\mathrm{O}$ quesito remuneração e benefícios foi o principal tópico de interesse destacado pela Metálica, em função do alto custo que os expatriados representam para a empresa;

- custo: o E16 (Analista de GPI Brasil) relata que o expatriado brasileiro custa, aproximadamente, quatro vezes mais que um empregado local (informação baseada em pesquisas científicas norte-americanas, às quais o entrevistado tem acesso). O E11 (Diretor de GP Corporativa Brasil) enfatiza que esse é seu principal interesse relacionado à expatriação;

- documentação: não há comunicação sobre este item entre a GPI do país de origem com a de destino, o que causa diversos percalços aos expatriados;

- preparação e treinamento (técnico, gerencial, cultural e linguístico): o treinamento linguístico é disponibilizado para o empregado e sua família, ficando os demais sob responsabilidade do empregado;

- $\quad$ acolhimento: não formalizado, mas deve ser realizado pelo gestor do país de origem;

- gestão de carreira: não há. No contrato de expatriação, é garantida a ocupação do cargo anteriormente ocupado. De modo informal, em alguns casos, é possibilitada a expectativa de carreira na empresa, caso o empregado apresente bons resultados em sua missão. Esse resultado, de modo informal, não é baseado no trabalho desenvolvido no exterior, mas no desempenho da unidade, ressaltaram alguns entrevistados;

- tributação dos rendimentos no exterior: as empresas Elétrica, Metálica e Ferro ressaltam que a legislação brasileira não é clara, permitindo diversos entendimentos quanto à tributação. A Elétrica proporciona acompanhamento jurídico para auxiliar nessa questão; $\mathrm{e}$

- $\quad$ surgimento de práticas informais que ainda não foram administradas pelas empresas (de origem e de recebimento): são feitas diversas viagens pelos empregados para mascarar a ausência do visto de trabalho; o expatriado acaba escolhendo um gestor como responsável por seus problemas e expectativas; a seleção informal ocorre em função do imediatismo do preenchimento do cargo, devido a diversas razões, como o despreparo da empresa para o retorno de um expatriado ou a não adaptação de um expatriado no exterior. A seleção informal também pode ocorrer, entre outros fatores, por haver poucas pessoas com tal preparação e disponibilidade ou até um eventual desconhecimento da empresa sobre as competências de seus empregados. 
Ademais algumas práticas foram abordadas pelos entrevistados, as quais, no entanto, não são implementadas pela GRHI: orientações locais, adaptação ao país estrangeiro, comunicação com a empresa de origem, avaliação de desempenho, gestão do conhecimento, aprendizado individual e organizacional, trabalho a ser desenvolvido na repatriação, orientações sobre as mudanças da empresa e valorização da pessoa/ aprendizado adquirido.

\subsection{Estudo de Caso da Plástico}

A Plástico, fundada em 1976, é um grupo industrial que produz embalagens rígidas de plástico para algumas das empresas mais reputadas no mundo. A empresa tem apresentado resultados com alto crescimento em seu volume de negócios e no número de trabalhadores, o que se mostra pelas experiências de internacionalização com sucesso (COSTA, 2005).

A expatriação para a Plástico parece estar bem estabelecida em termos de objetivos. É visível a importância de expatriar qualidade técnica, não tendo importância a origem ou o destino da pessoa, corroborando os estudos de Mercer (2010) e Freitas (2010). No entanto, as práticas de suporte da expatriação não estão formalizadas por completo na organização. Há planejamento e estrutura para auxiliar os gestores a conduzir esses processos, mas ainda falta formalizar as práticas de expatriação, como apontam Vianna (2008), Vianna e Souza (2009) e Lima e Braga (2010). O caráter burocrático das políticas e práticas de GP da subsidiária no Brasil é percebido justamente pela formação do E7 (Gerente GP Brasil), a qual se dá na área do Direito.

Dificuldades da expatriação advêm do fato de cada função, cada país e cada situação terem suas pecualiaridades (E3 - Gerente de GP). Isso dificulta a uniformização do processo, principalmente, ao lidar com as legislações e burocracias de cada país, sendo os impostos e o visto de trabalho problemas frequentes. Apesar dos fatores citados, a GP Global traçou uma diretriz para os gestores de cada unidade "começarem a mapear as pessoas que querem ser expatriados para qualquer outra unidade do grupo Plástico” (E7 - Gerente GP Brasil). Por isso, conforme observa o E7 (Gerente GP Brasil), a empresa precisa de um "processo de expatriação bem forte, robusto", pois "se a gente quer que os funcionários se movimentem, a gente vai ter que dar condições para que isso aconteça”. Ou seja, há conscientização da gestão sobre a importância e a necessidade de organizar o processo; não só como suporte para os expatriados, mas para a própria empresa poder suprir suas necessidades internacionais. 
Por vezes, a informalidade das práticas pode atrapalhar os planos da empresa. O E7 (Gerente GP Brasil) relata que possíveis expatriados foram procurar informações com outros colegas e ficaram preocupados com as condições de segurança do Brasil e postergaram os planos de uma expatriação. Esse contexto pode comprometer os negócios internacionais da empresa, pois se as pessoas deixarem de perceber a expatriação como vantajosa para elas, o número de pessoas dispostas a viajar pela empresa pode se tornar cada vez menor.

Caso a organização tivesse uma melhor apresentação da estrutura do país de destino, poderiam evitar esses problemas de comunicação. Nesse sentido, diversos autores, como Wong (2000), Pereira, Pimentel e Kato (2004) e Rego e Cunha (2009) apontam a importância de as empresas terem manuais culturais, cursos de informação (cultural, social e política) e programas de mentoria para melhorar a comunicação na organização. Ressalta-se, no entanto, que esses autores apontam o desenvolvimento desses cursos para os futuros expatriados, mas não focam nos possíveis expatriados.

De modo geral, práticas de análise do perfil do expatriado e da família; acompanhamento psicológico para o empregado e sua família; instruções sobre a cultura estrangeira; acompanhamento de adaptação ao país estrangeiro não são recorrentes na expatriação da Plástico. Além disso, as práticas referentes à repatriação, como trabalho a ser desenvolvido; orientações sobre as mudanças da empresa; tributação dos rendimentos no exterior; valorização da pessoa/ aprendizado adquirido; necessidade de novas práticas para os expatriados não estão estruturadas, visto que não há preocupação com a volta do empregado reflexo do tipo de expatriação adotado pela empresa. Algumas práticas são melhor detalhadas, na sequência:

- $\quad$ recrutamento e seleção: como a empresa tem um banco de dados das pessoas dispostas a expatriar, essa prática dificilmente é usada;

- contrato: após três meses de expatriação no país estrangeiro, o contrato é rompido e é iniciado o vínculo de trabalho como empregado local;

- trabalho a ser desenvolvido: normalmente, não há um objetivo estratégico para ser desenvolvido, mas uma função específica a ser preenchida;

- remuneração: não há vantagem financeira em ser expatriado, em comparação com o salário recebido no país de origem. Essa situação também foi relatada pelos gestores portugueses das outras empresas analisadas inicialmente na pesquisa, ao relatarem ganhar menos que os brasileiros mesmo quando esses últimos assumem funções de menor hierarquia. Apesar disso, consideram que há alto custo para a organização; 
- benefícios: são condizentes com o cargo assumido e não por ser expatriado. No entanto, um expatriado ressaltou a necessidade de solicitar auxílio moradia para conseguir se manter no Brasil, ao que a empresa não se opôs;

- documentação: responsabilidade da GPI; porém, na chegada ao país de destino, cabe à GP local resolver as pendências legais;

- preparação e treinamento (técnico, gerencial, cultural e linguístico): não há necessidade de treinamento técnico ou gerencial porque os empregados saem para o país de destino justamente para preencher uma posição que necessita desse conhecimento, daí não ser coerente a empresa enviar uma pessoa sem tal conhecimento. Também não há treinamento linguístico porque os portugueses já estudam inglês na educação básica e o treinamento cultural é responsabilidade do empregado;

- acolhimento e orientações locais: não há acolhimento. As orientações locais são realizadas pelo gestor do país de origem;

- comunicação com a empresa de origem: não há. Com a perda do vínculo de trabalho com o país de origem, não há necessidade de comunicação com ele;

- $\quad$ avaliação de desempenho: não há porque ele é considerado um empregado local;

- gestão do conhecimento: não é específica por ele ser expatriado;

- aprendizado individual e organizacional: como ele não retorna para a empresa como repatriado, não há práticas voltadas para a aprendizagem;

- gestão de carreira: é o único ponto que mostrou insatisfazer os expatriados. Apesar de não voltarem para seu país de origem, eles não querem ser expatriados para sempre e esperam que a empresa tenha desenhado uma perspectiva de carreira;

- $\quad$ surgimento de práticas informais ainda não administradas pelas empresas (de origem e de recebimento): além das diversas viagens como turista até obter o visto, os expatriados mostram a necessidade de repensar o regresso, o que, por vezes, ocasiona o retorno de um expatriado, mesmo que isso não seja política da empresa;

- novas práticas: o E8 (Gerente Geral Brasil - RJ) sugere que as expatriações comecem “por um país como o Brasil, Rússia, Ucrânia, países com dificuldades, para depois, quando chegam em países mais desenvolvidos, ao nível de recurso, Inglaterra, França, Estados Unidos, a pessoa é um melhor gestor".

O futuro do processo de expatriação nas organizações é incerto, conforme a visão dos entrevistados. Em função dos custos, o E1 (CEO e sócio-fundador), o E27 (Coadjuvante CEO e sócio-fundador do Grupo Turismo) e o E29 (Coadjuvante - Gestor de Projetos do 
Grupo Energia) consideram que o desfecho será o fim dos contratos empregatícios internacionais, sendo aqueles que buscam uma carreira internacional dentro da empresa encaixados na estrutura de destino como empregados nacionais. A tendência é não haver repatriação; política vigente na Plástico.

Por enquanto, o conceito de expatriação implementado pela Plástico tem sido suficiente, mostrando essa tendência de não haver repatriação. O E7 (Gerente GP Brasil) relata que "todos os expatriados são bem aceitos pelos nossos colaboradores e vice-versa também. A maioria, todos os processos de expatriação que nós fizemos, todos ficaram. Ainda não tivemos nenhum retorno".

\subsection{Políticas e Práticas de Expatriação: Comparação entre uma Empresa Brasileira e uma Empresa Portuguesa}

Perceberam-se diferenças no processo de expatriação nos dois casos, seja pelas estratégias de internacionalização e expatriação, seja pelo amadurecimento internacional da empresa, seja ainda pela legislação do país sede da matriz. Apesar de o processo ser diferente nos dois casos, nenhuma das duas empresas possui práticas consolidadas que atuem no processo de expatriação eficazmente, corroborando os estudos de Vianna (2008), Vianna e Souza (2009) e Lima e Braga (2010). Em função disso, surgem as práticas informais e o descontentamento de alguns empregados, sinalizando que esse descompasso pode diminuir o número de pessoas dispostas a expatriar, como também apontado em Gallon, Scheffer e Bitencourt (2013). O Quadro 2 mostra um resumo das políticas e práticas de expatriação encontradas nas duas empresas estudadas.

Quadro 2 - Políticas e Práticas de Expatriação na Elétrica e Plástico

\begin{tabular}{|c|c|}
\hline $\begin{array}{l}\text { Políticas e Práticas de Expatriação - } \\
\text { Caso Português }\end{array}$ & $\begin{array}{l}\text { Políticas e Práticas de Expatriação - Caso } \\
\text { Brasileiro }\end{array}$ \\
\hline $\begin{array}{l}\text { Análise do perfil; recrutamento e seleção; } \\
\text { análise do perfil familiar; auxílio e } \\
\text { acompanhamento psicológico para o } \\
\text { empregado e sua família; contrato; trabalho } \\
\text { a ser desenvolvido; custo; remuneração; } \\
\text { benefícios; documentação; cultura } \\
\text { estrangeira; preparação e treinamento } \\
\text { (técnico, gerencial, cultural e linguístico); } \\
\text { orientações locais; gestão do } \\
\text { conhecimento; acolhimento; }\end{array}$ & $\begin{array}{l}\text { Análise da demanda de mão de obra no } \\
\text { exterior, análise do perfil; recrutamento e } \\
\text { seleção; análise do perfil familiar; auxílio e } \\
\text { acompanhamento psicológico para o } \\
\text { empregado e sua família; contrato; trabalho a } \\
\text { ser desenvolvido; remuneração; benefícios; } \\
\text { custo; documentação; preparação e } \\
\text { treinamento (técnico, gerencial, cultural e } \\
\text { linguístico); cultura estrangeira; acolhimento; }\end{array}$ \\
\hline
\end{tabular}

(CONTINUA) 


\section{(CONTINUAÇÃO)}

\begin{tabular}{|c|c|}
\hline $\begin{array}{l}\text { adaptação ao país estrangeiro; } \\
\text { comunicação com a empresa de origem; } \\
\text { práticas informais; avaliação de } \\
\text { desempenho; aprendizado individual e } \\
\text { organizacional; gestão de carreira; } \\
\text { orientações sobre as mudanças da empresa; } \\
\text { tributação dos rendimentos; valorização da } \\
\text { pessoa; novas práticas para os expatriados. }\end{array}$ & $\begin{array}{l}\text { orientações locais; adaptação ao país } \\
\text { estrangeiro; comunicação com a empresa de } \\
\text { origem; avaliação de desempenho; gestão do } \\
\text { conhecimento; práticas informais; } \\
\text { aprendizado individual e organizacional; } \\
\text { gestão de carreira; trabalho a ser } \\
\text { desenvolvido; orientações sobre as mudanças } \\
\text { da empresa; tributação dos rendimentos no } \\
\text { exterior; valorização da pessoa/ aprendizado } \\
\text { adquirido; novas práticas para os expatriados. }\end{array}$ \\
\hline
\end{tabular}

Fonte: elaboração própria.

Em ambas as empresas, a falta de estrutura de expatriação está na perspectiva organizacional de que, com o tempo, as situações 'se ajeitam' (PEREIRA; PIMENTEL; KATO, 2004; LIMA; BRAGA, 2010). Entretanto, as empresas ainda não percebem as perdas organizacionais que um processo mal estruturado (MCCALL; HOLLENBECK, 2003) pode acarretar para a empresa, tanto em termos estratégicos como financeiros.

A política da Elétrica atende os diversos momentos que o expatriado passa no contexto internacional, embora careça de melhor estrutura para atender às necessidades dos empregados. Na visão da Plástico, não há expatriados em sua estrutura. Há empregados temporários requisitados na abertura de alguma unidade e convidados que aceitaram trabalhar em outra unidade da empresa. Essa concepção demanda tramitações burocráticas e algumas práticas de deslocamento de pessoal. Por essa perspectiva, compreende-se por que a estrutura do processo de expatriação é enxuta e tem poucas políticas e práticas, atendendo à preparação para viajar e à adaptação do expatriado no país de destino.

Ressalta-se que a denominação usual de expatriação está amadurecendo e assumindo outras configurações, como cidadão do mundo e equipes de suporte utilizadas pela Plástico na abertura de uma nova fábrica. Com isso, surge também a demanda por novas políticas e práticas para os expatriados, mesmo que eles percam seu significado inicial de empregados enviados pela empresa trabalhar em outro país.

O contexto do país de origem da empresa também influencia nas diferentes políticas e práticas entre os países. Além dos fatores burocracia, corrupção e jeitinho brasileiro, a diferença de infraestrutura, escolaridade e educação básica são aspectos que valem ser ressaltados. Portugal tem educação básica disponível para todos os cidadãos, e grande parte dos estudantes, ao concluir o período escolar, domina duas ou três línguas (português, francês 
e inglês). O Brasil carece de tal formação: mais de $49 \%$ da população adulta (25 a 64 anos) não completaram o ensino fundamental, $80 \%$ dos jovens com idade de 18 a 24 anos não têm acesso ao ensino superior e apenas $11,3 \%$ da população adulta têm curso superior completo (IBGE, 2012). Tal situação reflete os motivos do número reduzido de pessoas com fluência em inglês.

A comunicação por meio da língua inglesa é importante para atrair investidores estrangeiros. Quando ela não existe, surge a possibilidade de investimento em outras economias emergentes que já têm a fluência nesta língua, como a Índia. Como ressaltado por diversos entrevistados portugueses, é difícil trazer um expatriado para o Brasil que não fale português, porque as pessoas não têm condições de recebê-lo.

Essa situação não é coerente com a realidade portuguesa. O sistema brasileiro, aparentemente, já legitimou essa situação, visto que transfere para as empresas a responsabilidade da educação e instrução do empregado, frequentemente, denominada treinamento. As organizações brasileiras se sentem responsáveis em ensinar a segunda língua para seu empregado, enquanto o empregado português (e de outras nacionalidades) sai do colégio com fluência em outras línguas.

Tal 'treinamento' não é necessário para o empregado português, por exemplo. Quando a empresa estrangeira chega ao Brasil, não percebe como sua responsabilidade dar aquele preparo. Além disso, há, no banco de dados da empresa estrangeira, pessoas de outros países preparadas para assumirem esses desafios com menor custo. Exemplifica-se, assim, um dos motivos de a expatriação brasileira ter maior custo do que a de outros países.

Outro fator prende-se à legislação brasileira, que reconhece o empregado expatriado nas relações trabalhistas e exige das empresas recompensas financeiras do trabalho no exterior. Em Portugal, não há uma legislação específica para essa situação, possibilitando que a empresa tenha maior poder de barganha com os empregados. Tais fatos relatados relacionam-se com a diferença de glamourização da expatriação (LIMA; BRAGA, 2010; GALLON; SCHEFFER; BITENCOURT, 2013) entre os dois casos: para os brasileiros ser expatriado é um diferencial e status; enquanto para os portugueses é uma escolha. 


\section{CONSIDERAÇÕES FINAIS}

Frente ao investimento estrangeiro em diversos países, tanto nas economias mais desenvolvidas como nas emergentes, novos desafios são discutidos na GP e na gestão de expatriados. Consoante com esse panorama, o presente estudo teve o propósito de identificar e analisar as políticas e práticas de GP no processo de expatriação. De maneira sucinta, existem diferenças na gestão de expatriados das duas empresas analisadas, sobretudo em razão dos fatores sociais de cada país e dos objetivos propostos para o processo em questão.

As diferenças são percebidas na remuneração, pois algumas vantagens não são consideradas como benefícios. Por exemplo, na Plástico, carro e telefone celular são vistos como atrelados ao cargo em questão. Nela não há aumento salarial, mas os expatriados recebem auxílio-moradia, treinamento linguístico quando necessário (o que é muito raro, dada a maioria fluente em francês e inglês), férias, duas viagens para casa durante o ano e auxílio na documentação. A Elétrica, por sua vez, oferece aumento salarial, além de $25 \%$ de aumento previsto por lei, carro, telefone celular, acesso à internet, auxílio moradia, treinamento cultural e linguístico, férias, uma viagem por ano para casa (dependendo do contrato), apoio psicológico, quando solicitado, planejamento financeiro e auxílio tributário.

Como a Plástico adotou uma concepção diferente para seus empregados internacionais, as políticas e práticas desse processo são enxutas e de caráter burocrático. A expatriação não constitui um processo, mas a movimentação de um empregado de uma unidade para outra. Tal perspectiva difere daquela da Elétrica, a qual busca desenvolver um plano de expatriação para suportar seus empregados no contexto internacional. Ela entende que a expatriação ocorre pelo período de cinco anos e demanda uma gestão que zele por esse empregado enquanto ele a está servindo em outro país. Pode-se considerar que continuará tendo uma demanda por expatriações nas empresas estudadas, mas, ao mesmo tempo, amadurecendo conforme a demanda do contexto internacional e empresarial. Isso significa que o processo deve agregar novas concepções, estruturas, conceitos, significados, dentre outros fatores, porém não deixará de ser um processo presente nas organizações.

Como contribuição para a gestão, o estudo atenta que as empresas requerem uma GP e uma GPI que englobem a diversidade internacional e não foquem só nos expatriados. Elas precisam estar preparadas para receber os expatriados, os impatriados, os cidadãos do mundo e os empregados de outros países que, mesmo sem vínculos com a organização, demandam uma estrutura de GP de suporte, visto eles não serem empregados de origem daquela empresa. 
Esses últimos, denominados autoexpatriados, contribuem para a formação de equipes multiculturais, mas não fazem parte da GPI, pela inexistência de vínculo empregatício.

Então, qual é a função da GPI relativamente às políticas e práticas de expatriação? As empresas agora estão em um novo contexto, e não cabe à GPI cuidar apenas dos expatriados, mas de todas as pessoas internacionalizadas da empresa, para obter proveito dessa riqueza cultural. Entretanto, por vezes, a área deixa a desejar, restringindo-se a um papel meramente burocrático. O desafio da área reside em mostrar-se estratégica e em atender a todos os empregados, independentemente da nacionalidade, do vínculo empregatício de origem e de ser: expatriado, repatriado, cidadão do mundo ou autoexpatriado.

A literatura apresenta poucas perspectivas conceituais sobre a expatriação. As pesquisas baseiam-se nesses conceitos correntes e não discutem, com profundidade, as alterações e as implicações teóricas. Logo, os estudos não constroem uma teoria, porque apresentam os mesmos conceitos sem discuti-los, o que repercute em pouca contribuição teórica. Outra limitação teórica, não exclusiva do presente estudo, mas, de maneira geral, pertinente às pesquisas sobre GP e internacionalização realizadas em países emergentes como o Brasil é que a literatura utilizada é a americana, havendo poucos estudos bem estruturados, consolidados e contextualizados em países emergentes.

Em razão do exposto, este estudo ressalta empiricamente o desvinculamento do processo de expatriação da estratégia de internacionalização das empresas, o que se reflete em suas políticas e práticas pouco formalizadas, resultando em um processo mal planejado e de caráter operacional, acarretando a perda de um importante conhecimento organizacional e internacional.

Assim, sugere-se para estudos futuros desenvolver pesquisas em países emergentes de modo a entender a realidade da GP e de internacionalização das empresas, de acordo com o contexto de cada país. Nesse sentido, a estratégia de internacionalização adotada pela empresa pode influenciar o processo de expatriação, sendo oportuna a realização de pesquisas que façam essas investigações e relações. Também como oportunidade de pesquisa sobre as políticas e práticas de GP em expatriação, emerge a problemática da gestão de desempenho dos expatriados, bem como de outras práticas que possam auxiliar na estrutura do processo de expatriação. 


\section{REFERÊNCIAS}

ARAUJO, B. F. V. B. de; NUNES, I. M. Inteligência Cultural, Adaptação Transcultural e Desempenho de Expatriados: um estudo por meio de Equações Estruturais. In: ENCONTRO NACIONAL DOS PROGRAMAS DE PÓS-GRADUAÇÃ̃O EM ADMINISTRAÇÃO, 36, 2012. Rio de Janeiro. Anais... [S. I.]: 2012. CD-ROM.

ARMAGAN, S.; FERREIRA, M. P. The Impact of Political Culture on Firms' Choice of Exploitation-Exploration Internationalization Strategy. International Journal of Cross Cultural Management, v. 5, n. 3, p. 275-291, 2005.

BARDIN, L. Análise de conteúdo. 3. ed. Lisboa, Portugal: Edições 70, 2009.

BHATTACHARYYA, S. S.; JHA, S. Internationalization Strategy of Afcons: Planning and Implementation. South Asian Journal of Business and Management Cases, v. 6, n. 2, p. 135-149, 2017.

BIANCHI, E. M. P. G. Gestão e Carreira Internacional. Repatriação - construindo elos entre ciclos. In: ENCONTRO NACIONAL DOS PROGRAMAS DE PÓS-GRADUAÇÃO EM ADMINISTRAÇÃO, 35, 2011. Rio de Janeiro. Anais... [S. I.]: 2011. CD-ROM.

BROOKFIELD GLOBAL RELOCATION SERVICES. Global relocation trends: 2013 survey report. Disponível em: <http://www.brookfieldgrs.com/knowledge/grts_research/grts_media/2013_GRTS.pdf>. Acesso em: 10 jun. 2018.

BUENO, J. M.; FREITAS, M. E. de. As equipes multiculturais em subsidiárias brasileiras. In: ENCONTRO NACIONAL DOS PROGRAMAS DE PÓS-GRADUAÇÃO EM ADMINISTRAÇÃO, 36, 2012. Rio de Janeiro. Anais... [S. I.]: 2012. CD-ROM.

CARPES, A. de M.; SCHERER, F. L.; DINIZ, D.; BEURON, T. A. Expansão internacional para a China e seu reflexo no ajustamento internacional do executivo brasileiro expatriado. Revista Ibero-Americana de Estratégia, v. 10, n. 3, p. 22-48, set. /dez. 2011.

CHO, T.; HUTCHINGS, K.; MARCHANT, T. Key factors influencing Korean expatriates' and spouses' perceptions of expatriation and repatriation. The International Journal of Human Resource Management, v. 24, n. 5, p. 1051-1075, 2013.

COSTA, C. G. da. A cultura como fator dinamizador da economia: os investimentos portugueses no Brasil. Lisboa: Universidade Técnica de Lisboa, 2005. 
CRAIDE, A.; ABDALA, V. D.; BRITO, A. C. de. "Eu Vim de Lá (Mas Ninguém Avisou!)": reflexões sobre estratégias de Gestão de Pessoas voltadas à interculturalidade. In: ENCONTRO NACIONAL DOS PROGRAMAS DE PÓS-GRADUAÇÃO EM ADMINISTRAÇÃO, 34, 2010. Rio de Janeiro. Anais... [S. I.]: 2010. CD-ROM.

; FISCHER, T. M. D.; ADBALA, V. D.; BRITO, A. C. de. Intramobilidade e Interculturalidade Intranacional: desafios contemporâneos de profissionais brasileiros. In: ENCONTRO NACIONAL DOS PROGRAMAS DE PÓS-GRADUAÇÃO EM ADMINISTRAÇÃO, 35, 2011. Rio de Janeiro. Anais... [S. I.]: 2011. CD-ROM.

; SILVA, F. B. A mobilidade e a gestão intercultural nas organizações. Revista Pensamento Contemporâneo em Administração, v. 6, n. 1, jan. /mar., p. 105-123, 2012.

DAME, M. S.; VERRUCK, F.; LAZZARI, F.; GONÇALVES, R. B. Processo de expatriação e repatriação de funcionários em uma multinacional do setor Metalomecânico. In: ENCONTRO NACIONAL DOS PROGRAMAS DE PÓS-GRADUAÇÃO EM ADMINISTRAÇÃO, 35, 2011. Rio de Janeiro. Anais... [S. I.]: 2011. CD-ROM.

EMPRESA ELÉTRICA, 2014. Documentos internos. Disponível em: <http://www.empresaeletrica. net/br>. Acesso em: 03 jun. 2014.

FLICK, U. Métodos qualitativos na investigação científica. Lisboa: Monitor, 2002.

FREITAS, M. E. de. Expatriação Profissional: o desafio interdependente para empresas e indivíduos. Revista Eletrônica Gestão e Sociedade, v. 4, n. 9, set. /dez., 2010.

O imperativo intercultural na vida e na gestão contemporânea. Organização \& Sociedade, v. 15, n. 45, p. 79-89, 2008.

; DANTAS, M. O Estrangeiro e o novo grupo. Revista de Administração de Empresas, v. 51, n. 6, p. 601-608, 2011.

GALLON, S.; ANTUNES, E. D. Processo de expatriação: um modelo com fases e práticas. Revista Eletrônica de Estratégia \& Negócios, v. 8,54-85, 2015.

; SCHEFFER, A. B. B.; BITENCOURT, B. M. "Eu fui, voltei e ninguém viu": um estudo sobre a expectativa de carreira após a repatriação em uma empresa brasileira. Cadernos EBAPE. BR, v. 11, n. 1, p. 128-148, 2013. 
GONZÁleZ, J. M. R.; AÑEZ, M. E. M.; ALEXANDRE, M. L.; OlIVEIRA, J. A. de. Perspectivas Teóricas sobre a Adaptação do Expatriado: uma Abordagem Multidimensional. In: ENCONTRO NACIONAL DOS PROGRAMAS DE PÓS-GRADUAÇÃO EM ADMINISTRAÇÃO, 35, 2011. Rio de Janeiro. Anais... [S. I.]: 2011. CD-ROM.

GREER, T. W.; STILES, A. C. Using HRD to Support Repatriates: A Framework for Creating an Organization Development Strategy for Repatriation. Human Resource Development Review, v. 15, n. 1, p. 101-122, 2016.

HAAK-SAHEEM, W. The notion of expatriation in the United Arab Emirates: A contextual perspective. International Journal of Cross Cultural Management, v. 16, n. 3, p. 301-320, 2016.

HARVEY, M.; SPEIER, C.; NOVICEVIC, M. M. The evolution of strategic human resource systems and their application in a foreign subsidiary context. Asia Pacific Journal of Human Resources, v. 40, n. 3, p. 284-305, 2002.

HEMMASI, M.; DOWNES, M.. Cultural distance and expatriate adjustment revisited. Journal of Global Mobility: The Home of Expatriate Management Research, v. 1, n. 1, p. 72-91, 2013.

HOMEM, I. D.; DELLAGNELO, E. H. L. Novas formas organizacionais e os desafios para os expatriados. Revista de Administração de Empresas, v. 5, n. 1, jan. /jun., 2006.

; TOLFO, S. R. Práticas de gestão internacional de pessoas: compensação e seleção de expatriados em uma multinacional brasileira. Revista de Administração Contemporânea Eletrônica, v. 2, n. 2, p. 201-217, 2008.

IBGE - INSTITUTO BRASILEIRO DE GEOGRAFIA E ESTATÍSTICA, 2012. Indicadores. Disponível

em: <http://www.ibge.gov.br/home/mapa_site/mapa_site.php\#indicadores>. Acesso em 03 jun. 2013.

IRIGARAY, H. A. R.; VERGARA, S. C. Expatriados no Brasil: Diferentes Nacionalidades, Diferentes Percepções. Revista Gestão. Org, v. 8, n. 1, p. 49-60, jan. /abr., 2010.

JANGHORBAN, R.; ROUDSARI, R. L.; TAGHIPOUR, A. Qualitative Stud Health WellBeing, v. 9, 2014. Disponível em: <http://dx. doi.org/10.3402/qhw.v9.24152〉. Acesso em: 12 jul. 2018. 
JORNAL i, 2011. Entrevistado 1: "O maior problema que existe em Portugal é a classe empresarial”, Disponível em: <http://www.ionline. pt/artigos/dinheiro/entrevistado1-maiorproblema-existe-portugal-classe-empresarial>. Acesso em $13 \mathrm{dez} .2014$.

KUBO, E. K. de M.; BRAGA, B. M. Ajustamento intercultural de executivos japoneses expatriados no Brasil: um estudo empírico. Revista de Administração de Empresas, v. 53, n. 3, mai. /jun. p. 243-255, 2013.

LAZAROVA, M.; CALIGIURI, P. Repatriation and Knowledge Management. In: HARZING; A.; RUYSSEVELDT, J. V. International Human Resource Management. London: SAGE Publications, 2004.

LIMA, M. B.; BRAGA, B. M. Práticas de Recursos Humanos do Processo de Repatriação de Executivos Brasileiros. Revista de Administração Contemporânea, v. 14, n. 6, p. 1031$1053,2010$.

LISBOA, M. S. do A.; BRUNSTEIN, J. Desenvolvimento da competência de gestores brasileiros expatriados na Alemanha. In: ENCONTRO NACIONAL DOS PROGRAMAS DE PÓS-GRADUAÇÃO EM ADMINISTRAÇÃO, 34, 2010. Rio de Janeiro. Anais... [S. I.]: 2010. CD-ROM.

MACHADO, D. D. P. N.; STREHAU, S. Interculturalidade: expatriação como um envolvimento econômico ou social? Revista Eletrônica de Administração, v. 11, n. 12, 2008 .

MARANO, V. et al. Home country institutions and the internationalization-performance relationship: A meta-analytic review. Journal of Management, v. 42, n. 5, p. 1075-1110, 2016.

MAO, J.; SHEN, Y. Cultural identity change in expatriates: A social network perspective. Human Relations, v. 68, n. 10, p. 1533-1556, 2015.

MCCALL, M. JR.; HOLLENBECK, G. P. Desenvolvimento de Executivos Globais: as lições da experiência internacional. Porto Alegre: Bookman, 2003.

MERCER, 2010. International Assignment Survey - Portugal 2010. Disponível em: <http://www.mercer.com.br/press-releases/1387345>. Acesso em 10 jun. 2013.

NUNES, L. H.; VASCONCELOS, I. F. G. de; JAUSSAUD, J. Expatriação de Executivos. São Paulo: Thomsom Learning, 2008. 
ORSI, A.; BERTOIA, N. Formação de Equipes Globais por Empresas Brasileiras Internacionalizadas. In: ENCONTRO NACIONAL DOS PROGRAMAS DE PÓSGRADUAÇÃO EM ADMINISTRAÇÃO, 36, 2012. Rio de Janeiro. Anais... [S. I.]: 2012. CD-ROM.

; FISCHER, A. L. Políticas de remuneração para executivos expatriados por empresas brasileiras. In: ENCONTRO NACIONAL DOS PROGRAMAS DE PÓS-GRADUAÇÃO EM ADMINISTRAÇÃO, 35, 2011. Rio de Janeiro. Anais... [S. I.]: 2011. CD-ROM.

OSMAN-GANI, A. A. M.; HYDER, A. S. Repatriation readjustment of international managers: An empirical analysis of HRD interventions. Career Development International, v. 13 , n. 5 , p. $456-475,2008$.

PEREIRA, N. A. F.; PIMENTEL, R.; KATO, H. T. Expatriação e estratégia internacional: o papel da família como fator de equilíbrio na adaptação do expatriado. In: ENCONTRO NACIONAL DOS PROGRAMAS DE PÓS-GRADUAÇÃO EM ADMINISTRAÇÃO, 28, 2004. Curitiba. Anais... [S. I.]: 2004. CD-ROM.

RAMASWAMI, A.; CARTER, N. M.; DREHER, G. F. Expatriation and career success: A human capital perspective. Human Relations, v. 69, n. 10, p. 1959-1987, 2016.

REGO, A.; CUNHA, M. P. E. Manual De Gestão Transcultural De Recursos Humanos. Lisboa: Editora RH, 2009.

REIS, G. G. Desenvolvimento de competências de gestão de pessoas em subsidiárias: fatores de influência. In: ENCONTRO NACIONAL DOS PROGRAMAS DE PÓS-GRADUAÇÃO EM ADMINISTRAÇÃO, 36, 2012. Rio de Janeiro. Anais... [S. I.]: 2012. CD-ROM.

ROCHA, T. V.; BORINI, F. M. Mecanismos de transferência de conhecimento praticados por multinacionais: estudo comparativo entre multinacionais tradicionais e emergentes. In: SIMPÓSIO DE GESTÃO DA INOVAÇÃO TECNOLÓGICA, 25, 2008. Brasília. Anais... [S. I.]: 2008. CD-ROM.

SPOHR, N.; FLEURY, M. T. L. O Processo repatriação na visão de profissionais repatriados brasileiros. In: ENCONTRO NACIONAL DOS PROGRAMAS DE PÓS-GRADUAÇÃO EM ADMINISTRAÇÃO, 35, 2011. Rio de Janeiro. Anais... [S. I.]: 2011. CD-ROM.

STROH, L. K. Predicting turnover among repatriates: can organizations affect retention rates? The International Journal of Human Resource Management, v. 6, n. 2, mai. 1995. 
TAKEUCHI, R.; LI, Y.; WANG, M. Expatriates' performance profiles: examining the effects of work experiences on the longitudinal change patterns. Journal of Management, 2018.

TANURE, B.; BARCELlOS, E. P.; FLEURY, M. T. L. Psychic distance and the challenges of expatriation from Brazil. The International Journal of Human Resource Management, v. 20, n. 5, mai., p. 1039-1055, 2009.

; EVANS, P.; PUCIK, V. A Gestão de pessoas no Brasil: virtudes e pecados capitais estudos de caso. Rio de Janeiro: Elsevier, 2007.

TEIXEIRA, L. A. A.; SILVA, J. T. M.; LESSA, L. C. de C. Executivos brasileiros expatriados: percepções da nova função e influência da distância psíquica. REDES, v. 16, n. 1, p. 19-38, jan. /abr. 2011.

VIANNA, N. P. Uma análise sobre os processos de expatriação e repatriação em organizações brasileiras, 2008.127f. Dissertação (mestrado em Administração) Universidade do Vale do Rio dos Sinos, São Leopoldo, 2008.

; SOUZA, Y. S. de. Uma análise sobre os processos de expatriação e repatriação em organizações brasileiras. Revista de Administração e Contabilidade da Unisinos, v. 6, n. 4, p. 340-353, nov. /dez., 2009.

WONG, N. Mark your calender! Important tasks for international HR workforce. Costa Mesa, v. 79, n. 4, p. 72-74, 2000.

YIN, R. Estudo de caso: planejamento e métodos. 3. Ed. Porto Alegre: Bookman, 2010.

ZHANG, Y. Expatriate development for cross-cultural adjustment: Effects of cultural distance and cultural intelligence. Human Resource Development Review, v. 12, n. 2, p. 177-199, 2013. 